\title{
Hepatocyte growth factor modulates in vitro survival and proliferation of germ cells during postnatal testis development
}

\author{
A Catizone, G Ricci ${ }^{1}$, J Del Bravo and M Galdieri ${ }^{1}$ \\ Department of Histology and Medical Embryology, School of Medicine, University of Rome 'La Sapienza', Rome, Italy \\ ${ }^{1}$ Department of Experimental Medicine, Histology and Embryology Laboratory, School of Medicine, Second University of Naples, Naples, Italy \\ (Requests for offprints should be addressed to M Galdieri, Dip. Istologia ed Embriologia Medica, Via A. Scarpa 14, Roma 00161, Italy; \\ Email: michela.galdieri@uniroma1.it)
}

\begin{abstract}
The hepatocyte growth factor (HGF) is a pleiotropic cytokine that influences mitogenesis, motility and differentiation of many different cell types by its tyrosine kinase receptor c-Met. We previously demonstrated that the c-Met/HGF system is present and functionally active during postnatal testis development. We found also that spermatozoa express c-Met and that HGF has a positive effect on the maintenance of sperm motility. In the present paper, we extend our study on the germ cells at different stages of differentiation during the postnatal development of the testis. We demonstrate that c-met is present in rat spermatogonia, pachytene spermatocytes and round spermatids and that HGF significantly increases spermatogonial proliferation in 8- to 10-day-old prepubertal rats. At this age HGF does not affect Sertoli cells and peritubular myoid cells proliferation. In addition,
\end{abstract}

we studied the effect of the factor on germ cell apoptosis and we show that HGF prevents the germ cell apoptotic process. We also studied the effect of HGF on 18- to 20-day-old and 28- to 30-day-old rat testes. At these ages also the factor significantly increases germ cell duplication and decreases the number of apoptotic cells. However, the effect on programmed cell death is higher in the 8- to 10-day-old rats and declines in the older animals.

In conclusion, we report that rat germ cells (spermatogonia, pachytene spermatocytes and round spermatids) express c-met and that HGF modulates germ cell proliferating activity and apoptosis in vitro. These data indicate that the c-Met/HGF system is involved in male germ cell homeostasis and, consequently, has a role in male fertility. Journal of Endocrinology (2006) 189, 137-146

\section{Introduction}

During the first wave of spermatogenesis, germ cell apoptosis appears to be necessary for normal germ cell maturation. When apoptosis is eliminated, an abnormal number of germ cells accumulates in the seminiferous tubules and infertily occurs. Similar results, i.e. germ cell apoptosis and abnormal spermatogenesis, have been obtained by altering the expression of molecules regulating the apoptotic process (Furuchi et al. 1996, Rodriguez et al. 1997, Russell et al. 2002). Recently, it has been demonstrated that in the rat testis apoptosis peaks at 18 days of postnatal age, mediated by activation of caspase 3 and involves pachytene spermatocytes and type A spermatogonia in a stage-dependent manner (Jahnukainen et al. 2004).

In the adult rat testis, germ cell maturation is dependent on the hormonal levels. It has long been known that testosterone and follicle-stimulating hormone (FSH) regulate germ cell apoptosis, respectively inducing and preventing apoptosis of the germ cells (Madhwa Raj \& Dym 1976, Russell et al. 1987, Henriksen et al. 1995, 1996).
Recently, it has been reported that leukemia inhibitory factor (LIF) and stem cell factor (SCF) promote primordial germ cell survival preventing programmed cell death (Matsui et al. 1991, Pesce et al. 1993, Hakovirta et al. 1999, Yan et al. 2000). Endocrine and paracrine/autocrine factors also regulate germ cell proliferation: FSH stimulates spermatogonial proliferation both in vivo and in vitro (van Alphen et al. 1988, Arslan et al. 1993, Boitani et al. 1993) and many other testicular cytokines and growth factors affect germ cell proliferation (Pollanen et al. 1989, Parvinen et al. 1991, Boitani et al. 1995, Huleihel \& Lunenfeld 2004, Kubota et al. 2004, Puglisi et al. 2004).

Hepatocyte growth factor (HGF), originally identified as a mitogenic factor for hepatocytes (Nakamura et al. 1984, 1989), is a pleiotropic cytokine able to regulate the functional activities of many different cellular types (Zarnegar \& Michalopoulos 1995, Matsumoto \& Nakamura 1996). HGF is expressed during embryonic development (Sonnemberg et al. 1993) and we have previously demonstrated that HGF is synthesized by the embryonic mouse testis, induces testicular cell 
proliferation and acts as a morphogenetic factor (Ricci et al. 1999, 2002).

The multiple actions of HGF are mediated by its receptor, c-met, a transmembrane glycoprotein with tyrosine kinase activity, encoded by the MET protooncogene (Weidner et al. 1993, Hartmann et al. 1994). As we previously demonstrated, the HGF receptor is expressed in the postnatal rat testis and is detectable in the interstitial tissue and in the peritubular myoid cells of the seminiferous tubules. In the Sertoli cells, c-met expression is detectable in cells isolated from pubertal animals and is involved in postnatal testis development and function (Catizone et al. 1999, 2001). We also reported that in Sertoli cells HGF expression is developmentally regulated since its expression is only detectable at puberty (Catizone et al. 2005).

In humans, c-met is expressed in germ cells at different stages of differentiation and in spermatozoa (Depuydt et al. 1996, Herness \& Naz 1999). In rats, we have demonstrated that c-met is differently localized in spermatozoa isolated from the caput or the cauda of the epididymis and we have shown that HGF positively influences sperm motility (Catizone et al. 2002).

In the present paper, we report that mitotic and meiotic rat germ cells express c-met and we investigate the role of HGF on proliferation and apoptosis of germ cells during the first spermatogenetic wave.

\section{Materials and Methods}

\section{Animals}

Wistar rats were housed at the University of Rome 'La Sapienza'. All animal studies were conducted in accordance with the principles and procedures outlined in the NIH Guide for Care and Use of Laboratory Animals and were killed by $\mathrm{CO}_{2}$ asphyxia before testes removal. Ten male 8 - to 10-day-old rats of 18-22 g body weight (BW), five to ten male 18- to 20-day-old rats of 30-40 g BW and five male 28- to 30-day-old rats of 100-120 g BW were used for each experiment.

\section{Cell preparation and culture}

Germ cells suspension was prepared from 8- to 10-day-old and 28- to 30-day-old male Wistar rats, according to the technique previously described (Galdieri \& Monaco 1983).

To purify the spermatogonia, the cell suspension obtained from 8- to 10-day-old rats was cultured for $2 \mathrm{~h}$ on lectin-coated dishes to allow somatic cell adhesion according to a previously published technique (Scarpino et al. 1998). Floating germ cells were then collected and utilized for immunocytochemistry experiments. Utilizing 28to 30-day-old rats, purified populations of pachytene spermatocytes and round spermatids were obtained by sedimentation of the total germ cells suspension in an albumin gradient, according to the method of Lam et al. (1970). The fractions containing pachytene spermatocytes and round spermatids were collected, washed in modified Eagle's medium (MEM) (Gibco) and utilized for c-met detection. The purity of the fractions was evaluated by light microscopy and was $80-85 \%$ for pachytene spermatocytes and $90-95 \%$ for round spermatids.

\section{Immunocytochemistry}

Germ cells prepared as indicated above were suspended in saline solution and approximately 15000 cells were air dried on a slide, fixed in ethanol-acetone (1:1) according to the suggestions of the antibody manufacturer for 10 min at $-20{ }^{\circ} \mathrm{C}$, treated with 5\% BSA (Sigma-Aldrich Chemical Co) for $30 \mathrm{~min}$ at room temperature to minimize the non-specific binding and were then exposed to a polyclonal antibody against the carboxy terminus of c-met (sc-162, 1:50 dilution; Santa Cruz Biotechnology, Santa Cruz, CA, USA) for $16 \mathrm{~h}$ at $4{ }^{\circ} \mathrm{C}$. At the end of the incubation period, the cells were washed extensively with PBS and incubated for $45 \mathrm{~min}$ at room temperature with a fluorescein isothiocyanate-conjugated goat anti-rabbit antiserum (Sigma-Aldrich Chemical Co). The cells were rinsed again with PBS and mounted in buffered glycerol $(\mathrm{pH} 9)$. As a negative control, the primary antibody was omitted and substituted with rabbit immunoglobulin $\mathrm{G}$ or 10 -fold excess by weight of the blocking peptide (sc-162P; Santa Cruz Biotechnology). Samples were analyzed using a Zeiss Axioplan fluorescence microscope.

\section{Western blotting}

Germ cells isolated from at least five rats were purified as described in the 'Cell preparation and culture' section and centrifuged for $20 \mathrm{~min}$ at $300 \times \mathbf{g}$. The pellet was washed twice and suspended in a solution containing PBS, 1\% Igepal, $0 \cdot 1 \%$ sodium dodecyl sulfate (SDS), $0 \cdot 5 \%$ sodium deoxycholate, $2 \mathrm{mM}$ phenyl-methyl-sulfonyl-fluoride (PMSF), $5 \mu \mathrm{g} / \mathrm{ml}$ aprotinin, $500 \mu \mathrm{g} / \mathrm{ml}$ leupeptin (SigmaAldrich Chemical $\mathrm{Co}$ ) and sonicated on ice. The sonicated cells were centrifuged for $2 \mathrm{~min}$ at $15000 \mathrm{~g}$ at $4{ }^{\circ} \mathrm{C}$ and the supernatant was stored at $-20^{\circ} \mathrm{C}$ until use. Protein concentration was determined by the method of Bradford (1976). Usually, $100 \mu \mathrm{g}$ protein were solubilized in boiling Laemmli buffer (Laemmli 1970) containing 5\% $\beta$-mercaptoethanol and then separated on 7\% SDS PAGE. The proteins were electrotransferred to a nitrocellulose membrane. Non-specific binding was blocked by incubation with 5\% BSA in TBS buffer $(20 \mathrm{mM}$ Tris $\mathrm{pH} 7 \cdot 6$, $150 \mathrm{mM} \mathrm{NaCl}$ ). After blocking, the membrane was incubated with rabbit anti-met polyclonal antibody against the carboxy terminus of c-met p140 of mouse origin (Santa Cruz sp-260, 1:1000) or with a mouse 
monoclonal antibody anti-tubulin (Sigma-Aldrich T5168, $1: 3000)$ in TBS, $5 \%$ BSA overnight at $4{ }^{\circ} \mathrm{C}$. The membrane was washed three times with TBS for 20 min each at room temperature and then incubated with the APconjugated secondary antibody (Sigma-Aldrich Chemical Co) $(1: 2000)$ for $1 \mathrm{~h}$ at room temperature. After washing with TBS, immunocomplexes were detected by Western blot chemiluminescence reagent (CDP-star; NEN, Boston, MA, USA) following the manufacturer's instructions.

\section{Organ culture}

Fragments of approximately $1 \mathrm{~mm}^{3}$ were isolated from ten testes of 8- to10-day-old rats, or from eight testes of 18to 20- or 28- to 30-day-old rats and placed on steel grids previously coated with $2 \%$ agar. Grids were then placed in organ culture dishes (Falcon, Becton Dickinson, Lincoln Park, NJ, USA) with $0.8 \mathrm{ml}$ medium necessary to wet the grid. The chemically defined medium was MEM (Gibco) supplemented with glutamine $(2 \mathrm{mM})$, Hepes $(15 \mathrm{mM})$, non-essential amino acids, penicillin $(100 \mathrm{IU} / \mathrm{ml})$ and streptomycin $(100 \mu \mathrm{g} / \mathrm{ml})$. HGF $(150 \mathrm{U} / \mathrm{ml}$; SigmaAldrich $\mathrm{Co}$ ) was added to the culture medium when indicated. Samples were cultured for $24 \mathrm{~h}$ at $32{ }^{\circ} \mathrm{C}$ in a humidified atmosphere of $5 \% \mathrm{CO}_{2}$ in air. Bromodeoxyuridine (BrdU) was then added to the culture medium for $4 \mathrm{~h}$ before harvesting. The protocol specified by the manufacturer (Cell Proliferation Kit; Amersham Corp) was used. After culture, the samples were washed twice in PBS, fixed overnight in Bouin's fixative, dehydrated, embedded in paraffin, sectioned at a thickness of $8 \mu \mathrm{m}$ and processed according to the manufacturer to detect BrdUlabeled cells. The sections were counterstained with hemalum, dehydrated, mounted with Histovitrex (Carlo Erba, Milano, Italy) and analyzed using a Zeiss Axioscope microscope. The number of BrdU-positive cells in at least 300 transverse tubules of three different experiments was counted.

The sections were also utilized for TUNEL assay. The TUNEL method utilized for apoptotic cell analysis was the Q-BIOgene Apoptosis Kit (ApopTag Peroxidase; MP Biochemicals, Italy). As positive controls, samples were treated with DNase I. Negative controls were carried out omitting terminal deoxynucleotidyl transferase enzyme in the reaction mixture. The sections were counterstained with hemalum, dehydrated, mounted with Histovitrex (Carlo Erba) and analyzed using a Zeiss Axioscope microscope. At the different ages, at least three experiments in triplicate were performed and the number of TUNELpositive cells $/ 250$ transverse tubules was evaluated.

At all the ages studied the morphology of the samples appeared well preserved. Somatic and germ cells were identified by cell size, nuclear morphology and localization within the seminiferous tubules, according to the description by Chiarini-Garcia et al. (2003).
Statistical analysis

Data were analyzed using the Sigma Plot 5.0 software package (Systat Software GmbH, Erkrath, Germany); Student's $t$-test was employed.

\section{Results}

c-met expression in germ cells

The presence of c-met protein was detected by immunolocalization on spermatogonia obtained in three separate isolations from 8- to 10-day-old rats (Fig. 1D) and on pachytene spermatocytes and round spermatids isolated from animals of 28- to 30 days of age (Fig. 1E, F). In all the cell types the protein was present and showed a spotted distribution. Phase contrast microscopy of the same cells is shown in Fig. 1 (A-C) and negative controls are presented in Fig. 1 (G-J). The controls were invariably negative using either isotype serum or the blocking peptide. The presence of c-met on three different preparations of spermatocytes and spermatids was also evaluated by Western blotting. Figure 2 shows that the anti-met antibody detects a positive single band of $145 \mathrm{kDa}$, coincident in weight with the mature c-met $\beta$ chain, in the proteins extracted from both germ cell populations (Fig. 2A,B). The tubulin content of the cells was also evaluated. Therefore, the presence of c-met was confirmed by two different techniques. Liver proteins were used as a positive control and gave the same positive signal. An additional signal at a molecular weight close to the c-met single-chain precursor is also present in the liver (Fig. 2C).

\section{HGF effects}

At least three separate experiments were performed to investigate the role of HGF on germ cell duplication and apoptosis. Small explants of testes isolated from animals of different ages have been cultured for $24 \mathrm{~h}$ in medium alone or supplemented with HGF $(150 \mathrm{U} / \mathrm{ml})$. In Fig. 3 the results obtained utilizing prepubertal rats (8- to 10-days-old) are presented. The left panel of the figure (A) shows the morphological appearance of the control (C) and the HGF-treated samples (HGF) in which it is evident that the presence of HGF in the culture medium increases the number of proliferating cells. The number of BrdUpositive cells present in the tubules has been counted and in the HGF-treated samples spermatogonia proliferate to almost twice as many in respect to the germ cells present in the control samples (Table 1). To ascertain whether HGF also affected the somatic cells of the tubules, the number of BrdU-labeled Sertoli cells and peritubular myoid cells, identified by morphological criteria, has been counted (250 transverse tubules of both samples). 

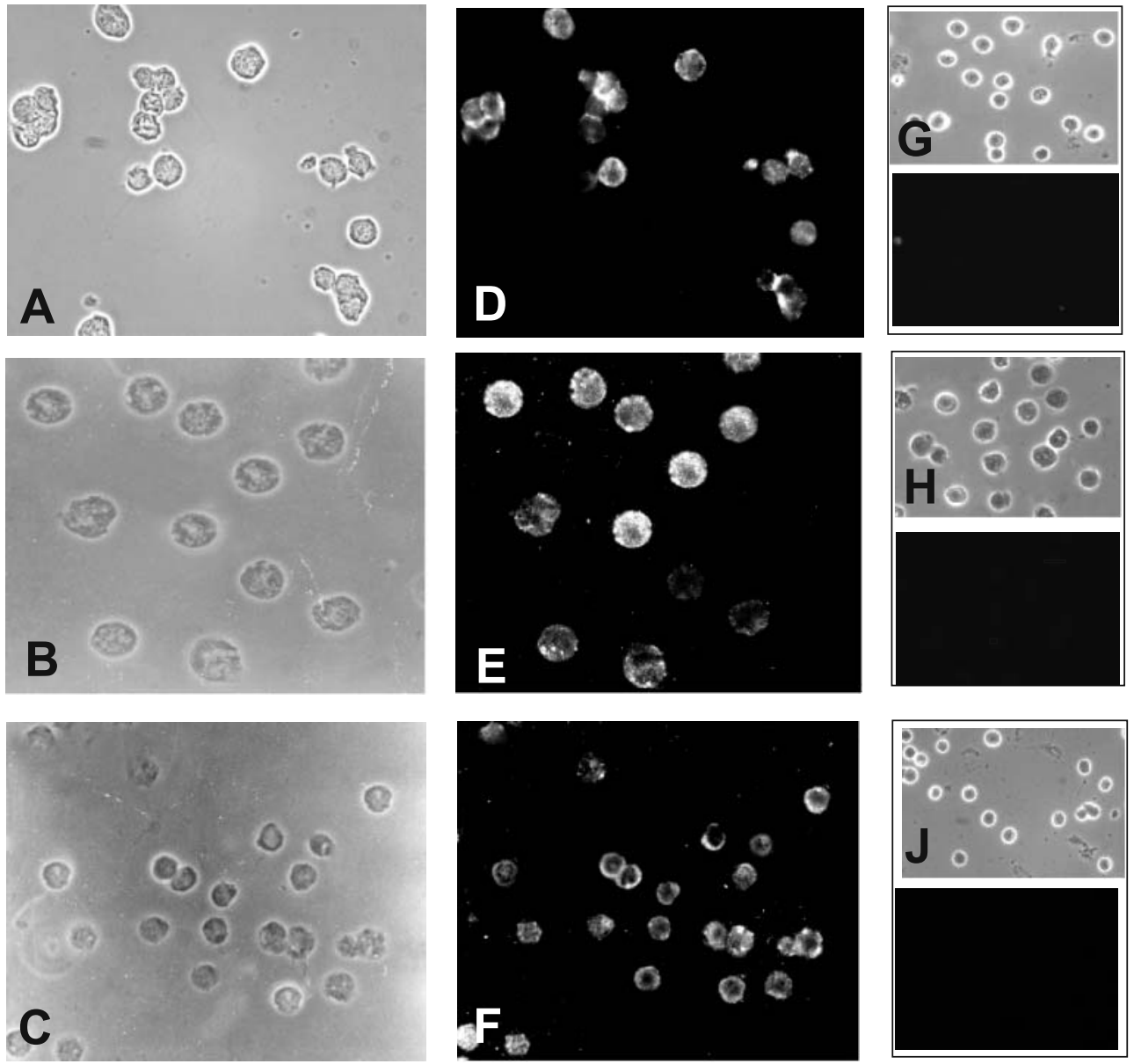

Figure 1 c-met distribution in germ cells isolated from rat testes. Phase contrast microscopy of spermatogonia $(A)$, pachytene spermatocytes $(B)$ and round spermatids $(C)$ is presented. C-met indirect immunofluorescence on the same cells $(D, E, F)$ is also shown. Negative controls $(G, H$, J, lower panels) and relative phase contrasts $(\mathrm{G}, \mathrm{H}, \mathrm{J}$, upper panels) were obtained using the blocking peptide against the anti-met antibody.

The number of proliferating Sertoli and peritubular cells appears not to be modified by HGF treatment (Table 1).

Different sections of the same samples were used to detect the apoptotic cells present in the control and the HGF-treated samples. The morphology, shown in the right hand panels of Fig. 3, appears well preserved and only apoptotic germ cells were detected. The quantification of the effects obtained is shown in Fig. 4A. In the HGF-treated samples the number of BrdU-labeled cells (at least 300 transverse tubules/sample counted) was increased more than $100 \%$ whereas the number of TUNELpositive cells (250 transverse tubules/sample counted) was strongly reduced (approximately 75\%).

The morphology of fragments isolated from testes of 18- to 20-day-old rats (late prepubertal rats) is shown in Fig. 5. Cell proliferation (Fig. 5A) and cell apoptosis (Fig. $5 \mathrm{~B})$ are presented in the figure. At this age the number of
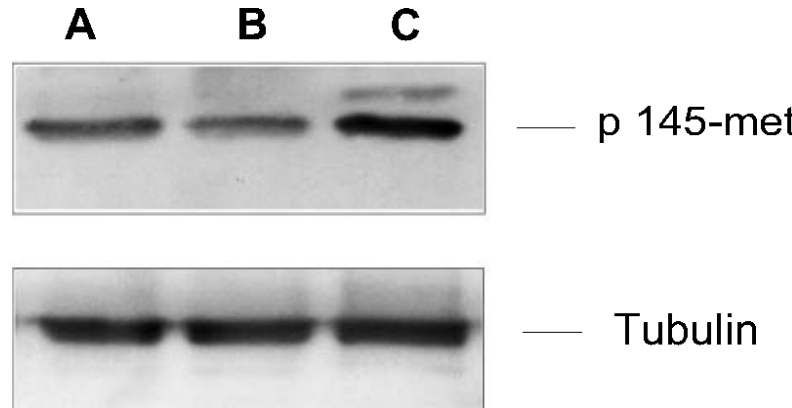

Tubulin

Figure 2 Western blot analysis of proteins extracted from pachytene spermatocytes (A) and round spermatids (B). Proteins were separated by SDS-PAGE under reducing conditions. The molecular weight of c-met $\beta$ chain $(145 \mathrm{kDa})$ is indicated. Rat liver proteins $(\mathrm{C})$ were used as a positive control. The tubulin content of the same samples was also evaluated and the results of one representative experiment out of three performed are shown. 
A
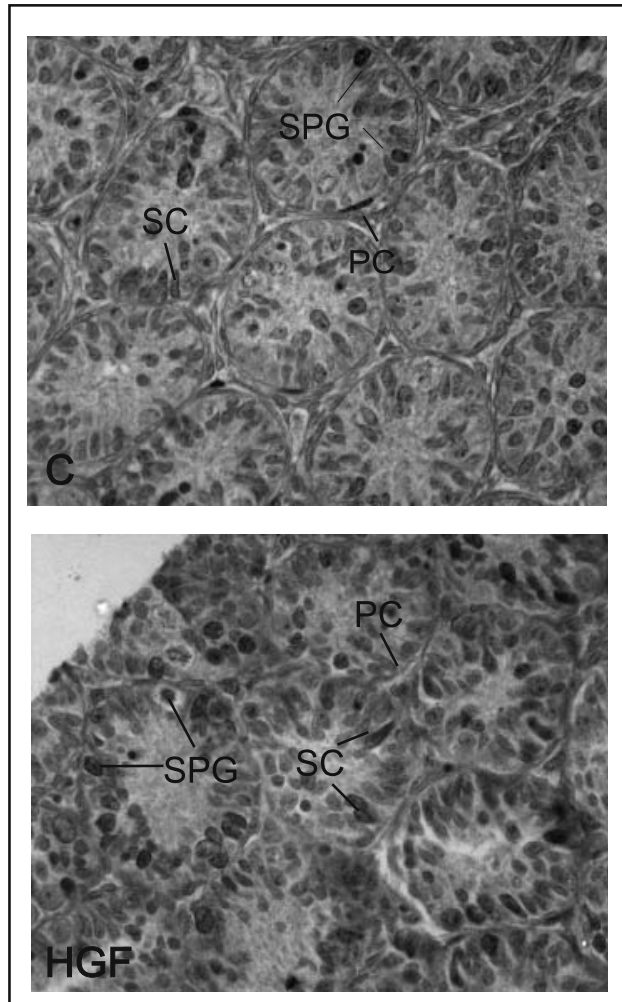

B
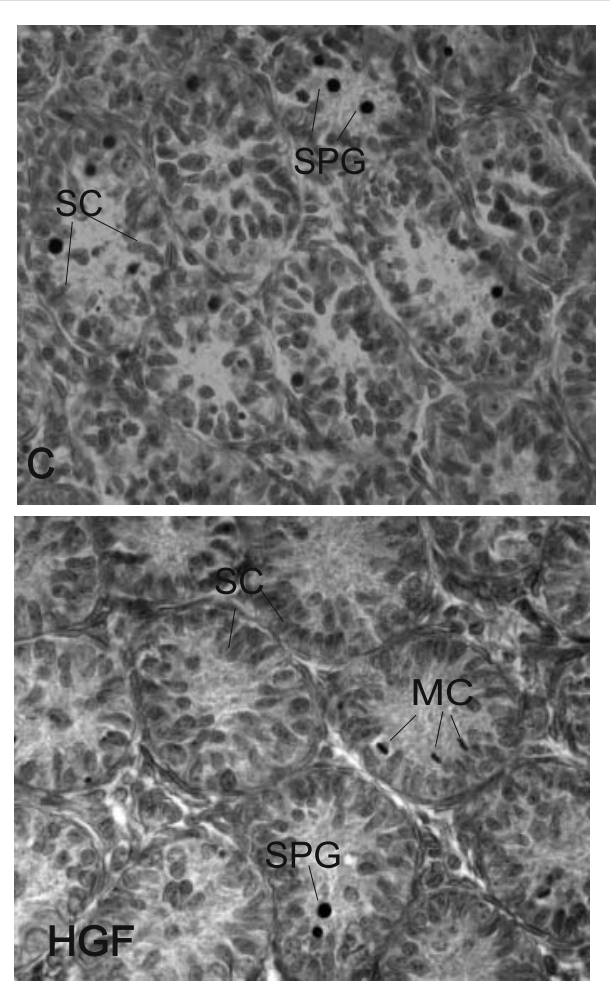

Figure 3 Photomicrographs of histological sections of testis fragments from 8- to 10-day-old rats (original magnification $\times 200$ ) cultured for $24 \mathrm{~h}$ in control medium (C) and HGF-supplemented medium (HGF).

(A) Sections were immunostained with anti-BrdU. (B) Sections of the same samples in which apoptotic cells were stained by the TUNEL method. Sertoli cells (SC), peritubular cells (PC) and spermatogonia (SPG) are indicated in both panels. MC, mitotic cells.

proliferating and apoptotic cells is increased compared with the 8- to 10-day-old rats and is confined to the germ cells. In the HGF-treated samples (Fig. 4B), the number of BrdU-labeled germ cells was more than $100 \%$ increased whereas the number of apoptotic germ cells was decreased (approximately 35\%, Fig. 4B).

Similar experiments were performed utilizing testes isolated from 28- to 30-day-old rats and the morphology of the samples (pubertal rats) is presented in Fig. 6A and B. Also at this age we found that the number of proliferating cells is higher with respect to the younger animals, and HGF is able, significantly, to stimulate germ cell proliferation (Fig. 4C). Germ cell apoptosis is slightly increased at this age compared with 18- to 20-day-old testes and appears to affect both spermatogonia and meiotic germ cells. Also in these pubertal rats, germ cell death is significantly prevented by HGF (approximately 60\%) (Fig. 4C).

\section{Discussion}

In the present paper, we report that rat germ cells at different stages of differentiation express the HGF receptor. We previously reported that the HGF receptor is

Table 1 Number of BrdU-labelled Sertoli cells, spermatogonia and peritubular myoid cells present in 250 transverse tubules of control and HGF-treated samples

\begin{tabular}{|c|c|c|c|c|}
\hline \multirow{2}{*}{ Treatme } & Number of tubules & Sertoli Cells & Spermatogonia & Peritubular cell \\
\hline & & & & \\
\hline Control & 250 & 357 & 362 & 45 \\
\hline HGF & 250 & 363 & 730 & 49 \\
\hline
\end{tabular}



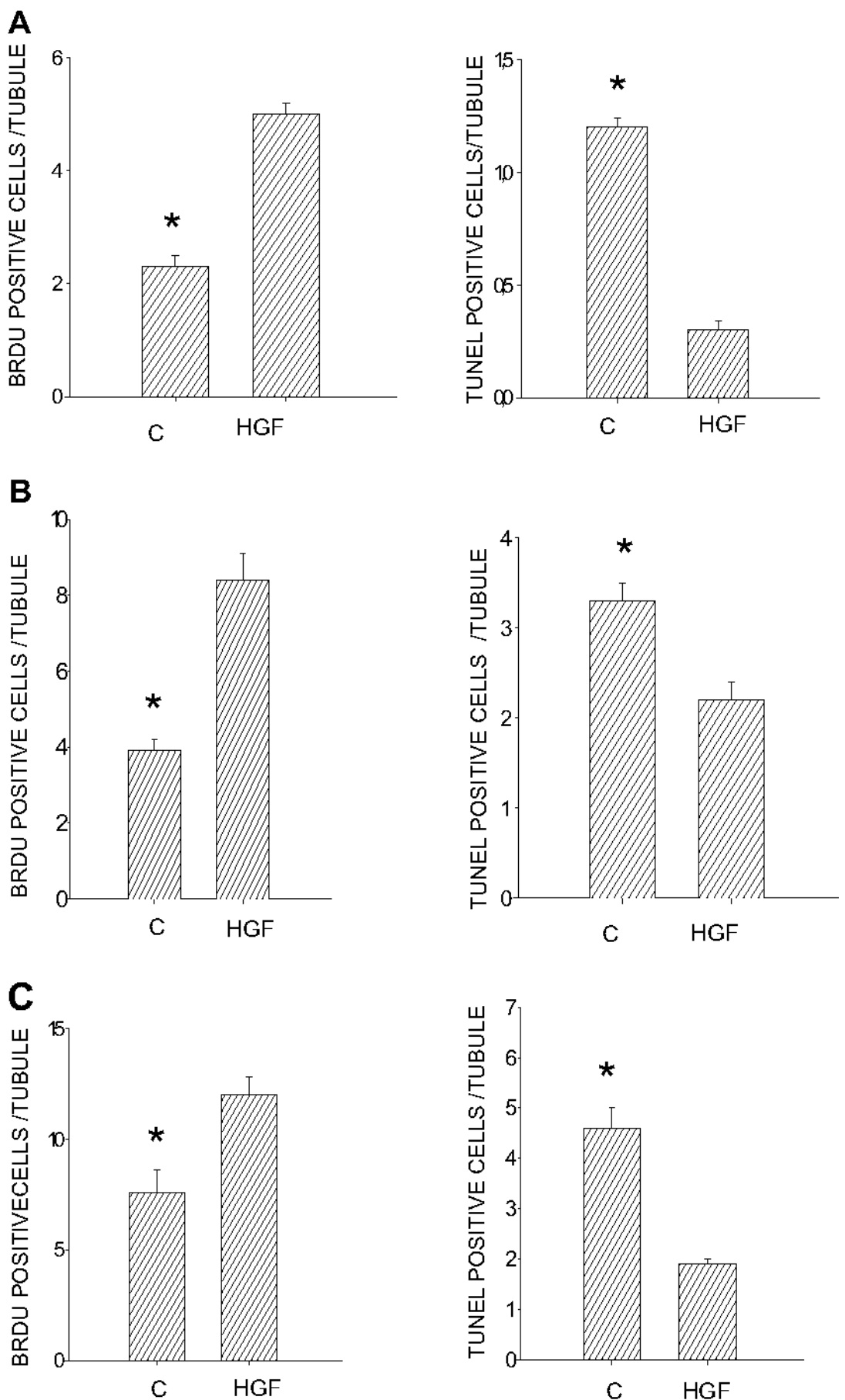

Figure 4 Number of BrdU- and TUNEL-positive cells present in testes from 8- to 10-day-old (A), 18- to 20-day-old (B) and 28- to 30-day-old (C) rats. On the left hand side of the three panels the mean of BrdU-labeled cells/tubule is shown. In all the panels, the mean \pm S.E. of positive cells in 300 tubules of each of the three experiments performed is reported. In $\mathrm{A}$ and $\mathrm{B},{ }^{*} P<0.001$ compared with HGF values; in $\mathrm{C},{ }^{*} \mathrm{P}<0.05$ compared with HGF values. On the right hand side of the panels the mean of apoptotic cells/tubule is reported. In all the panels the mean \pm S.E. of positive cells in 250 tubules of each of the three experiments performed is reported. ${ }^{*} P<0 \cdot 001$ compared with HGF values. 
A

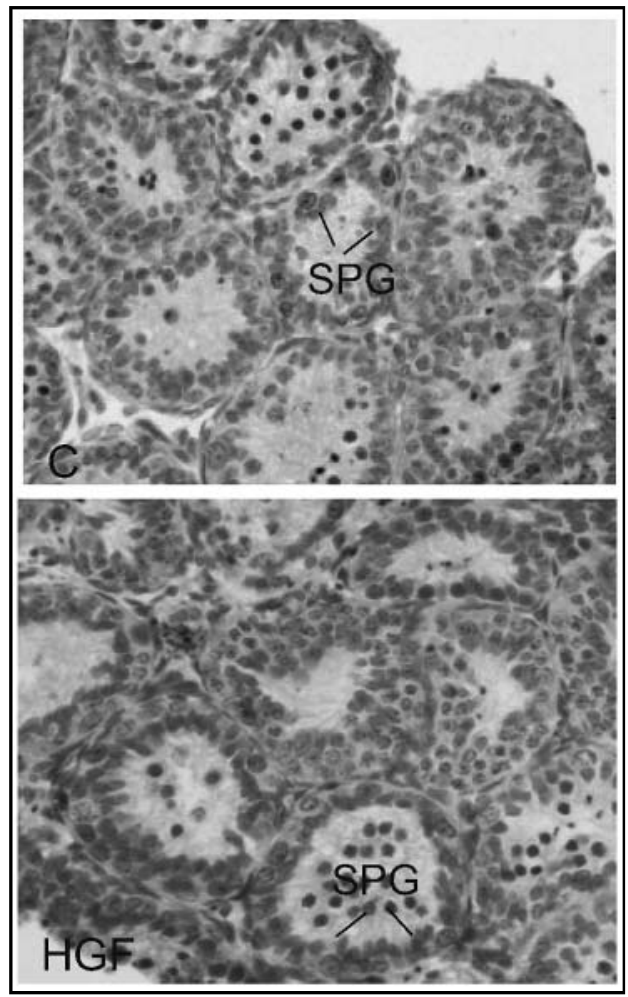

B

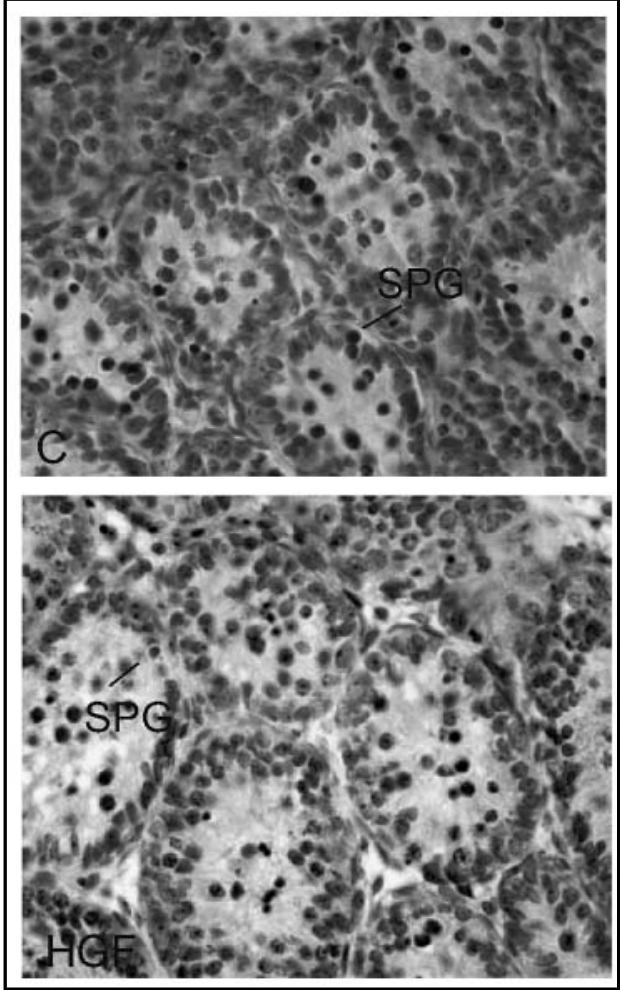

Figure 5 Photomicrographs of histological sections of testis fragments from 18- to 20-day-old rats (original magnification $200 \times$ ) cultured for $24 \mathrm{~h}$ in control medium (C) and HGF-supplemented medium (HGF).

(A) Sections were immunostained with anti-BrdU. (B) Sections of the same samples in which apoptotic cells are stained by the TUNEL method. SPG, spermatogonia.

expressed in rat spermatozoa (Catizone et al. 2002) and we now extend our investigation demonstrating, by different techniques, that c-met is present in rat spermatogonia, pachytene spermatocytes and round spermatids. It was shown in humans that differentiating germ cells, as well as spermatozoa, express c-met (Depuydt et al. 1996, Herness \& Naz 1999); however, the role of this factor was not investigated. We now report the presence of the receptor on rat germ cells and investigate the functional role of HGF in these cells. By means of culture of small testicular explants we have found that HGF in vitro significantly increases spermatogonial proliferation in both prepubertal and pubertal rats. In the 8- to 10-day-old animals Sertoli cells and peritubular myoid cells also proliferate. Therefore, we counted all the proliferating cells and our data demonstrate that HGF exclusively stimulates spermatogonial duplication, as the number of proliferating Sertoli cells and peritubular myoid cells are not significantly different in the control and in the HGF-treated cells. On the other hand, the number of BrdU-labeled spermatogonia is approximately double in the tubules cultured in the presence of HGF. It is well known that several hormones influence spermatogonial apoptosis and duplication. Testosterone and FSH regulate germ cell apoptosis (Henriksen et al. 1995, 1996) probably acting via somatic cells considering the absence on the germ cells of their respective receptors (Heckert \& Griswold 1991, de Kretser et al. 1998). FSH stimulates spermatogonial proliferation both in vivo and in vitro (van Alphen et al. 1988, Arslan et al. 1993, Boitani et al. 1993) and many other growth factors such as LIF, interleukins and SCF regulate germ cell duplication (for a review see Huleihel \& Lunenfeld 2004). We have previously reported that HGF induces proliferation of the embryonic testicular cells (Ricci et al. 2002) and other authors have reported that HGF exerts mitogenic and anti-apoptotic action in endothelial cells (Nakagami et al. 2001). The results here presented confirm that HGF has to be included in the list of bioactive molecules acting on spermatogonial duplication in postnatal life, as previously reported by Goda et al. (2004). Moreover, we show that the effect of HGF on germ cell proliferation is exerted during the entire first wave of spermatogenesis.

We have also studied the effect of the factor on germ cell apoptosis and have shown that HGF prevents the germ cell apoptotic process. This effect is at its maximum 
A

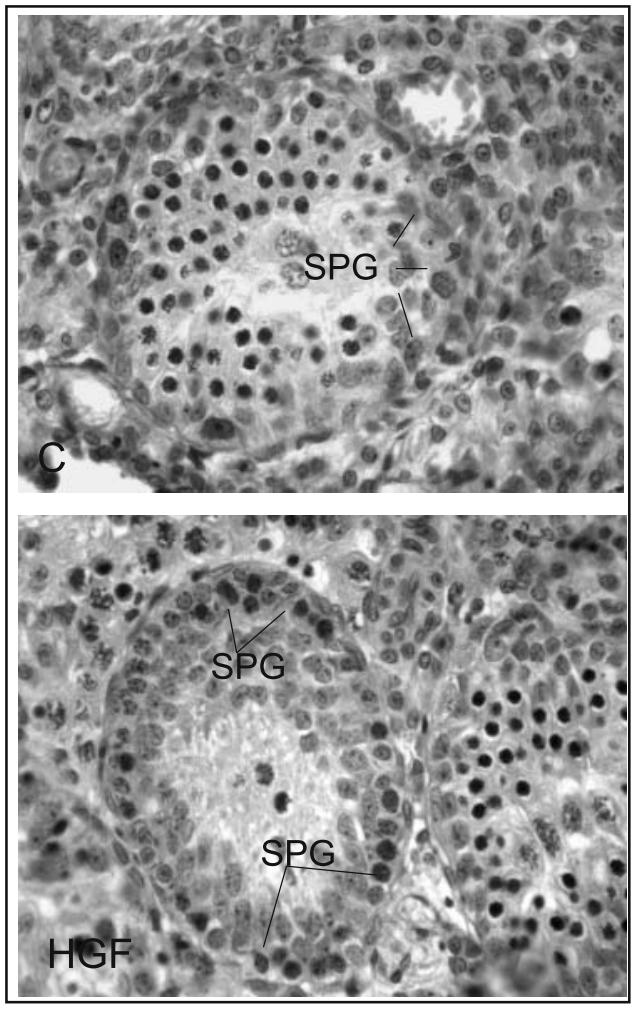

B

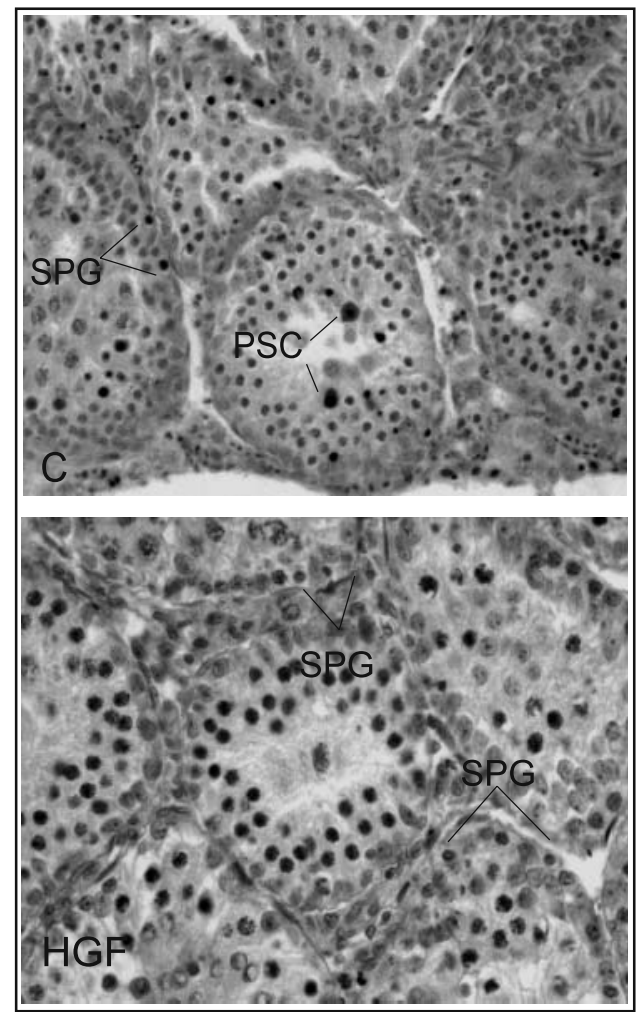

Figure 6 Photomicrographs of histological sections of testis fragments from 28- to 30-day-old rats cultured for $24 \mathrm{~h}$ in control medium (C) and HGF-supplemented medium (HGF). (A) Sections were immunostained with anti-BrdU (original magnification $\times 400$ ). (B) Sections of the same samples in which apoptotic cells were stained by the TUNEL method (original magnification $\times 200$ ). SPG, spermatogonia; PSC, pachytene spermatocytes.

( $75 \%$ reduction of apoptosis) in the 8 - to 10 -day-old rats and declines in the older animals. The lowest protective effect (35\% reduction of apoptosis) was found in late prepubertal rats and this finding is probably due to the fact that the highest level of apoptosis has been described at this age (Jahnukainen et al. 2004) or to the presence of a more complex network of pro-apoptotic and antiapoptotic factors present in the older animals. For example, it is known that paracrine factors secreted by round spermatids promote the survival of spermatocytes in stages VII-VIII of the spermatogenetic process (Zhao et al. 1998). On the other hand, a physiological apoptotic wave during the first spermatogenetic maturation is necessary for normal spermatogenesis in the adult individuals and it has been hypothesized that spermatogonial apoptosis during the establishment of spermatogenesis is necessary for the maintenance of a proper ratio between germ cells and Sertoli cells (Rodriguez et al. 1997).

It has recently been reported that in the adult rat testis, after experimental induction of cryptorchidism, adenovirally transferred HGF gene expression decreases the number of apoptotic germ cells (Goda et al. 2004).
However, these data have been obtained in an experimentally complex way. The authors obtained transient overexpression of HGF in the testis and, a long time after orchidopexy, they reported a decrease in apoptosis in the adenoviral-injected rats. Our data, obtained by culturing testicular fragments isolated from rats of different ages, demonstrate that HGF modulates survival and proliferation of germ cells during the first spermatogenetic wave of postnatal rat testis development.

In conclusion, in the present paper we report that rat germ cells (spermatogonia, pachytene spermatocytes and round spermatids) express the HGF receptor, c-met. Moreover, we report that HGF modulates germ cell metabolic activities in vitro, positively regulating germ cell proliferation and decreasing the number of apoptotic germ cells.

\section{Acknowledgements}

The authors wish to thank Drs C Boitani and F Palombi for their helpful discussions. 


\section{Funding}

This work was supported by the grants from 'Ministero per l'Università e la Ricerca Scientifica e Tecnologica' (Cofin 2002) to Michela Galdieri. The authors declare that there is no conflict of interest that would prejudice the impartiality of this scientific work.

\section{References}

Arslan M, Weinbauer GF, Schlatt S, Shahab M \& Nieschlag E 1993 FSH and testosterone, alone or in combination, initiate testicular growth and increase the number of spermatogonia and Sertoli cells in a juvenile non-human primate (Macaca mulatta). Journal of Endocrinology 136 235-243.

Boitani C, Politi MG \& Menna T 1993 Spermatogonial cell proliferation in organ culture of immature rat testis. Biology of Reproduction 48 761-767.

Boitani C, Stefanini M, Fragale A \& Morena AR 1995 Activin stimulates Sertoli cell proliferation in a defined period of rat testis development. Endocrinology 136 5438-5444.

Bradford MM 1976 A rapid and sensitive method for the quantitation of microgram quantities of protein utilizing the principle of protein-dye binding. Analytical Biochemistry 72 248-254.

Catizone A, Ricci G, Arista V, Innocenzi A \& Galdieri M 1999 Hepatocyte growth factor and c-MET are expressed in rat prepuberal testis. Endocrinology 140 3106-3113.

Catizone A, Ricci G \& Galdieri M 2001 Expression and functional role of hepatocyte growth factor receptor (C-MET) during postnatal rat testis development. Endocrinology 142 1828-1834

Catizone A, Ricci G \& Galdieri M 2002 Functional role of hepatocyte growth factor receptor during sperm maturation. Journal of Andrology 23 911-918.

Catizone A, Ricci G \& Galdieri M 2005 HGF and postnatal testis development. Molecular and Cellular Endocrinology 241 32-40.

Chiarini-Garcia H, Raymer A \& Russell LD 2003 Non-random distribution of spermatogonia in rats: evidence of niches in the seminiferous tubules. Reproduction 126 669-680.

de Kretser DM, Loveland KL, Meinhardt A, Simorangkir D \& Wreford N 1998 Spermatogenesis. Human Reproduction 13 1-8.

Depuydt CE, Zalata A, de Potter CR, van Emmelo J \& Comhaire FH 1996 The receptor encoded by the human C-MET oncogene is expressed in testicular tissue and on human spermatozoa. Molecular Human Reproduction 2 2-8.

Furuchi T, Masuko K, Nishimune Y, Obinata M \& Matsui Y 1996 Inhibition of testicular germ cell apoptosis and differentiation in mice misexpressing $\mathrm{Bcl}-2$ in spermatogonia. Development 122 1703-1709.

Galdieri M \& Monaco L 1983 Evidence of protein secretion by cultured pachytene spermatocytes. Cellular Differentiation 13 49-55.

Goda K, Fujisawa M, Shirakawa T, Dobashi M, Shiota G, Zhang ZJ, Gotoh A \& Kamidono S 2004 Adenoviral-mediated HGF expression inhibits germ cell apoptosis in rats with cryptorchidism. Journal of Gene Medicine 6 869-876.

Hakovirta H, Yan W, Kaleva M, Zhang F, Vanttinen K, Morris PL, Soder M, Parvinen M \& Toppari J 1999 Function of stem cell factor as a survival factor of spermatogonia and localization of messenger ribonucleic acid in the rat seminiferous epithelium. Endocrinology 140 1492-1498.

Hartmann G, Weidner KM, Schwarz H \& Birchmeier W 1994 The motility signal of scatter factor/hepatocyte growth factor mediated through the receptor tyrosine kinase met requires intracellular action of Ras. Journal of Biological Chemistry $26921936-21939$.

Heckert LL \& Griswold MD 1991 Expression of follicle-stimulating hormone receptor mRNA in rat testes and Sertoli cells. Molecular Endocrinology $\mathbf{5}$ 670-677.

Henriksen K, Hakovirta H \& Parvinen M 1995 Testosterone inhibits and induces apoptosis in rat seminiferous tubules in a stage-specific manner: in situ quantification in squash preparations after administration of ethane dimethane sulfonate. Endocrinology 136 3285-3291.

Henriksen K, Kangasniemi M, Parvinen M, Kaipia A \& Hakovirta H 1996 In vitro, follicle-stimulating hormone prevents apoptosis and stimulates deoxyribonucleic acid synthesis in the rat seminiferous epithelium in a stage-specific fashion. Endocrinology 137 2141-2149.

Herness EA \& Naz RK 1999 Presence and tyrosine phosphorylation of c-met receptor in human sperm. Journal of Andrology 20 640-647.

Huleihel M \& Lunenfeld E 2004 Regulation of spermatogenesis by paracrine/autocrine testicular factors. Asian Journal of Andrology $6259-268$.

Jahnukainen K, Chrysis D, Hou M, Parvinen M, Eksborg S \& Soder O 2004 Increased apoptosis occurring during the first wave of spermatogenesis is stage-specific and primarily affects midpachytene spermatocytes in the rat testis. Biology of Reproduction 70 290-296.

Kubota H, Avarbock MR \& Brinster RL 2004 Growth factors essential for self-renewal and expansion of mouse spermatogonial stem cells. PNAS 101 16489-16494.

Laemmli UK 1970 Cleavage of structural proteins during the assembly of the head of bacteriophage T4. Nature 227 680-685.

Lam DM, Furrer R \& Bruce WR 1970 The separation, physical characterization, and differentiation kinetics of spermatogonial cells of the mouse. PNAS 65 192-199.

Madhwa Raj HG \& Dym M 1976 The effects of selective withdrawal of FSH or LH on spermatogenesis in the immature rat. Biology of Reproduction 14 489-494.

Matsui Y, Toksoz D, Nishikawa S, Nishikawa S, Williams D, Zsebo K \& Hogan BL 1991 Effect of Steel factor and leukaemia inhibitory factor on murine primordial germ cells in culture. Nature 353 $750-752$.

Matsumoto K \& Nakamura T 1996 Emerging multipotent aspects of hepatocyte growth factor. Journal of Biochemistry (Tokyo) 119 591-600.

Nakagami H, Morishita R, Yamamoto K, TaniyamaY, Aoki M, Matsumoto K, Nakamura T, Kaneda Y, Horiuchi M \& Ogihara T 2001 Mitogenic and antiapoptotic actions of hepatocyte growth factor through ERK, STAT3, and AKT in endothelial cells. Hypertension 37 581-586.

Nakamura T, Nawa K \& Ichihara A 1984 Partial purification and characterization of hepatocyte growth factor from serum of hepatectomized rats. Biochemical and Biophysical Research Communications 122 1450-1459.

Nakamura T, Nishizawa T, Hagiya M, Seki T, Shimonishi M, Sugimura A, Tashiro K \& Shimizu S 1989 Molecular cloning and expression of human hepatocyte growth factor. Nature 342 440-443.

Parvinen M, Soder O, Mali P, Froysa B \& Ritzen EM 1991 In vitro stimulation of stage-specific deoxyribonucleic acid synthesis in rat seminiferous tubule segments by interleukin-1 alpha. Endocrinology 129 1614-1620.

Pesce M, Farrace MG, Piacentini M, Dolci S \& De Felici M 1993 Stem cell factor and leukemia inhibitory factor promote primordial germ cell survival by suppressing programmed cell death (apoptosis). Development 118 1089-1094.

Pollanen P, Soder O \& Parvinen M 1989 Interleukin-1 alpha stimulation of spermatogonial proliferation in vivo. Reproduction and Fertility Development 1 85-87.

Puglisi R, Montanari M, Chiarella P, Stefanini M \& Boitani C 2004 Regulatory role of BMP2 and BMP7 in spermatogonia and Sertoli cell proliferation in the immature mouse. European Journal of Endocrinology 151 511-520. 
Ricci G, Catizone A, Innocenzi A \& Galdieri M 1999 Hepatocyte growth factor (HGF) receptor expression and role of HGF during embryonic mouse testis development. Developmental Biology $216340-347$.

Ricci G, Catizone A \& Galdieri M 2002 Pleiotropic activity of hepatocyte growth factor during embryonic mouse testis development. Mechanism of Development 118 19-28.

Rodriguez I, Ody C, Araki K, Garcia I \& Vassalli P 1997 An early and massive wave of germinal cell apoptosis is required for the development of functional spermatogenesis. EMBO Journal 16 2262-2270.

Russell LD, Alger LE \& Nequin LG 1987 Hormonal control of pubertal spermatogenesis. Endocrinology 120 1615-1632.

Russell LD, Chiarini-Garcia H, Korsmeyer SJ \& Knudson CM 2002 Bax-dependent spermatogonia apoptosis is required for testicular development and spermatogenesis. Biology of Reproduction 66 950-958.

Scarpino S, Morena AR, Petersen C, Froysa B, Soder O \& Boitani C 1998 A rapid method of Sertoli cell isolation by DSA lectin, allowing mitotic analyses. Molecular and Cellular Endocrinology 146 121-127.

Sonnemberg E, Meyer D \& Birckmeier C 1993 Scatter factor/hepatocyte growth factor and its receptor, the C-MET tyrosine kinase, can mediate a signal exchange between mesenchyme and epithelia during mouse development. Development $123223-225$

van Alphen MM, van de Kant HJ \& de Rooij DG 1988 Folliclestimulating hormone stimulates spermatogenesis in the adult monkey. Endocrinology 123 1449-1455.

Weidner KM, Sachs M \& Birchmeier W 1993 The Met receptor tyrosine kinase transduces motility, proliferation, and morphogenic signals of scatter factor/hepatocyte growth factor in epithelial cells. Journal of Cell Biology 121 145-154.

Yan W, Suominen J, Samson M, Jegou B \& Toppari J 2000 Involvement of $\mathrm{Bcl}-2$ family proteins in germ cell apoptosis during testicular development in the rat and pro-survival effect of stem cell factor on germ cells in vitro. Molecular and Cellular Endocrinology 165 115-129.

Zarnegar R \& Michalopoulos GK 1995 The many faces of hepatocyte growth factor: from hepatopoiesis to hematopoiesis. Journal of Cell Biology 129 1177-1180.

Zhao GQ, Liaw L \& Hogan BL 1998 Bone morphogenetic protein $8 \mathrm{~A}$ plays a role in the maintenance of spermatogenesis and the integrity of the epididymis. Development 125 1103-1112.

Received 7 December 2005

Accepted 16 December 2005 